\title{
"VAZIO PLENO": DESCOLONIZAÇÃO DO PENSAMENTO E POSSIBILIDADES CRIATIVAS NOS CURSOS DE GRADUAÇÃO EM DIREITO
}

\section{Carolina Grant Pereira*}

\section{RESUMO}

O presente trabalho se propôs a investigar as condições de possibilidade para o alcance do que se convencionou chamar de "vazio pleno", enquanto decorrência da descolonização do pensamento e abertura para possibilidades criativas nos cursos de graduação em Direito no Brasil. Para tanto, realizou uma análise crítico-comparativa das contribuições teóricas de dois importantes autores para o pensamento filosófico ocidental. Concluiu lançando as bases para um novo ethos, com foco nas potencialidades advindas do "lançar-se no nada" (Heidegger) ou "lançar-se no imenso vazio", através da "entrega" e do "desaparecimento" no samadhi (Nachmanovitch), revalorizando, assim, o ócio criativo.

PALAVRAS-CHAVE: Direito; Arte; Técnica; Criatividade; Entrega.

\section{"FULL VOID": DECOLONIZATION OF THOUGHT AND CREATIVE POSSIBILITIES IN GRADUATION COURSES OF LAW}

\begin{abstract}
The present work set out to investigate the conditions of possibility for reaching what is known as a "full void", as a consequence of the decolonization of thought and openness to creative possibilities in undergraduate courses in Law in Brazil. To do so, it performed a criticalcomparative analysis of the theoretical contributions of two important authors to Western philosophical thought. It concluded by laying the foundations for a new ethos, focusing on the potentialities of "throwing oneself into nothingness" (Heidegger) or "launching into the immense void" through "surrender" and "disappearance" in samadhi (Nachmanovitch), thus revaluating creative leisure.
\end{abstract}

KEYWORDS: Law; Art; Technics; Creativity; Surrender.

\footnotetext{
* Doutoranda em Direito pela Universidade Federal da Bahia (UFBA). Mestre em Direito Privado pela Universidade Federal da Bahia (UFBA). Especialista em Filosofia e Direitos Humanos pela Universidade Cândido Mendes (UCAM-AVM). Graduada em Direito pela Universidade Federal da Bahia (UFBA). Professora da Faculdade Baiana de Direito (FBD). Pesquisadora nas áreas de Gênero, Diversidade, Bioética, Direito Civil, Direitos Humanos, Internacional e Propedêutica Jurídica (IED, Filosofia do Direito, Antropologia e Sociologia Jurídicas, Hermenêutica e Metodologia). E-mail: carolinagrant@ hotmail.com.
} 


\section{INTRODUÇÃO}

O presente trabalho científico parte do enfrentamento do seguinte problema de pesquisa: a verificação, nos últimos anos, de uma crise de qualidade na produção de conhecimento em Direito no Brasil, como decorrência, também, de uma crise do ensino jurídico (NOBRE, 2011; GUSTIN, DIAS, 2006).

Por outro, lado, falar sobre criatividade pode, muitas vezes, recair no lugar comum, mas Stephen Nachmanovitch, em “Ser Criativo” (1993), realiza uma abordagem que vai além da análise do criar em si e acaba por promover uma verdadeira reflexão filosófica sobre a atitude do indivíduo perante a vida de modo criativo. Esta abordagem nos remeteu às teorizações de Martin Heidegger sobre a metafísica, a questão da técnica e da verdade enquanto alétheia, assim como a uma discussão já travada em trabalhos anteriores sobre ethos colonizatório e civilizacional.

Desse contexto surgiu a proposta do presente trabalho: investigar as condições de possibilidade para o alcance do que se convencionou chamar de "vazio pleno", enquanto decorrência da descolonização do pensamento (ruptura com o ethos colonizatório) e abertura para possibilidades criativas (lançamento das bases para um novo ethos), de modo a estimular os alunos a criarem, não mais apenas reproduzirem, nos cursos de graduação em Direito.

Para tanto, partir-se-á da investigação sobre o que se acredita estar na base do ethos colonizatório, ainda predominante, que é a razão instrumental, do breve estudo de suas origens, desdobramentos, atributos e limitações, para, então, analisar crítico e, ao final, comparativamente as contribuições teóricas dos dois supracitados autores, importantes quer para o pensamento filosófico ocidental contemporâneo (Martin Heidegger), quer para a discussão sobre criatividade (Stephen Nachmanovitch).

Por fim, pretende-se estabelecer e defender uma aproximação entre o "lançar-se no imenso vazio" - através da "entrega" e do "desaparecimento" no samadhi proposto por Nachmanovitch - e o "lançar-se no nada" - como suspensão e nadificação do ente ao apontar para a sua totalidade, discutidos por Heidegger -, fixando-os, ainda, dentre as condições de possibilidade de um novo ethos, lúdico e criativo, que resgate e revalorize o "vazio" em sua plenitude criadora. 


\section{DELINEANDO O PROBLEMA NO ÂMBITO DA GRADUAÇÃO DOS CURSOS DE DIREITO}

Em artigo intitulado “Apontamentos sobre a pesquisa em Direito no Brasil”, Marcos Nobre (2011), professor da Universidade Estadual de Campinas (UNICAMP), afirma que é possível qualificar "o estágio alcançado por essa área de pesquisas como de 'relativo atraso' em relação ao das demais disciplinas das ciências humanas" (NOBRE, 2011, p. 3). Isso porque, embora a

pesquisa em Direito tenha alcançado elevados patamares quantitativos, em termos de produção acadêmica, não acompanhou este mesmo crescimento em termos qualitativos, o que foi verificado em outras Ciências Humanas. A tese defendida por Marcos Nobre em face do problema apontado, portanto, fundamenta-se em duas hipóteses discutidas pelo autor: 1) de um lado, uma das principais causas da crise experienciada pelo Direito encontrar-se-ia no seu isolamento em relação às demais humanidades; 2) de outro, justificar-se-ia pela confusão entre ensino e prática jurídica nos cursos de Direito.

Sobre a primeira hipótese, que aborda a relação entre o Direito e as demais disciplinas das Ciências Humanas, constatou-se a consideração de dois fatores por Nobre: a) o "princípio da antiguidade" (tradicionalismo); b) e o "poder simbólico" do Direito (autossuficiência), "já que no Brasil o direito é a disciplina universitária mais antiga, bem como a mais diretamente identificada com o exercício do poder político", de modo que se constituiu parecendo arrogar para si, dentre as humanidades, "a posição de 'ciência rainha', [...] voltando-se aos demais ramos de conhecimento somente na medida em que importavam para o exame jurídico dos temas em debate" (NOBRE, 2011, p. 5).

Dessa forma, o que se pôde perceber foi que o Direito, ao procurar constituir-se como ciência autônoma, levou a sua autonomia ao extremo, a ponto de isolar-se relativamente às demais ciências, inclusive considerando encontrar-se em posição de destaque (superior em status e poder simbólico), o que reforçaria a desnecessidade do auxílio das demais áreas do saber na construção do seu próprio conhecimento.

Já sobre a segunda hipótese, que trata da confusão entre teoria, prática e ensino jurídicos, seria possível concluir, com Nobre e para além de seu trabalho, que: a) de um lado, embora a universidade esteja preparando (ou ao menos procurando preparar) o estudante para o ingresso no mercado de trabalho, não o está para a reflexão sobre o seu objeto de estudo (o Direito); b) por outro, tem sido notada uma grande confusão, por parte de alunos e 
professores, entre artigo científico (lógica da reflexão) e parecer jurídico (lógica da persuasão), de modo que a construção do conhecimento acaba sendo direcionada para a defesa de determinadas teses, através da aposta no convencimento retórico, e não para a construção de novas respostas e abordagens. Daí porque a crise da produção seria decorrência da crise do ensino; um ensino ainda focado na reprodução de conhecimentos consolidados e que, por isso mesmo, restringe as perspectivas de análise dos problemas que chegam aos estudantes e profissionais do Direito.

Miracy Gustin e Maria Tereza Dias (2006), por sua vez, também apontam para o déficit de qualidade na produção jurídico-acadêmica, ao afirmarem que:

\begin{abstract}
Os julgamentos dos projetos de pesquisa em Direito no âmbito do CNPq, dos quais participo como integrante do comitê assessor nessa área, têm sido monocórdicos e recorrentes. Invariavelmente, a cada sessão, $90 \%$ dos pedidos são rejeitados logo de início, por falta de rigor metodológico. Mal formulados em seus objetivos, inconsistentes em termos analíticos e pouco convincentes em sua fomentação teórica, esses projetos revelam o grau de desinformação de seus autores [...]. Este problema é de caráter estrutural e está ligado à má qualidade do ensino jurídico, tanto na graduação quanto, em alguns casos, na própria pós-graduação. Excessivamente formalista e restrito ao aprendizado de códigos ultrapassados, ele não acompanhou as sucessivas transformações sofridas pelas instituições de Direito no âmbito de uma sociedade marcada pela velocidade, intensidade e profundidade de suas mudanças. Acima de tudo, o ensino jurídico se destaca pelo flagrante envelhecimento de seus esquemas cognitivos e pelo esgotamento de seus paradigmas teóricos. (GUSTIN, DIAS, 2006, p. V - grifo nosso).
\end{abstract}

O que fazer, então, diante desta crise do ensino e da produção de conhecimento em Direito? A aposta deste trabalho é na compreensão e despertar da criatividade, sobretudo através da vivência da ludicidade, no âmbito dos cursos de graduação em Direito, conforme se verá.

\title{
3. A IDENTIFICAÇÃO DO ETHOS PRODUTIVO OU COLONIZATÓRIO: A TÉCNICA E A RAZÃO INSTRUMENTAL
}

Quando Karl Marx analisou o modo de produção capitalista e o processo de alienação decorrente da divisão social do trabalho, mais especificamente da crescente separação entre o trabalho intelectual e o trabalho manual, levando à padronização e repetição, já alertava para o quanto o trabalhador "não se sente feliz, mortifica seu corpo e arruína seu espírito no trabalho que é obrigado a fazer, que é externo a ele" (QUINTANEIRO et al., 2003, p. 52).

Segundo Marx e Engels (1975, p. 28), a classe dominante, isto é, a dos possuidores dos meios de produção, retira do trabalho realizado pelo operariado "todo o caráter 


\section{"VAZIO PLENO": DESCOLONIZAÇÃO DO PENSAMENTO E POSSIBILIDADES CRIATIVAS NOS CURSOS DE GRADUAÇÃO EM DIREITO}

substantivo e fazem com que perca todo atrativo para ele. O produtor converte-se num simples apêndice da máquina e só se exigem dele as operações mais simples, mais monótonas e de mais fácil aprendizagem”.

Outro clássico da Sociologia, Max Weber, que recebe de Marx, como influência teórica, o estudo do tema do capitalismo e de suas consequências na organização da sociedade, ao refletir acerca do "desencantamento do mundo", também aponta para a falta de percepção crítica do indivíduo sobre o que acontece à sua volta e para a automação de seus comportamentos.

A Escola de Frankfurt ${ }^{1}$, que institucionalizou e difundiu a chamada "Teoria Crítica"2, retoma, por sua vez, a discussão de Weber acerca do processo de racionalização na modernidade, em especial após a publicação da obra "Dialética do Esclarecimento" (1947), de dois dos grandes nomes desta Escola, Theodor Adorno e Max Horkheimer, consagrando a crítica ao que identificou como razão técnica ou instrumental.

Em "A Dialética do Esclarecimento", Adorno e Horkheimer revisam a dialética de Hegel para compreender como a proposta emancipatória do iluminismo ("esclarecimento"), associada, incialmente, à busca por autonomia e autodeterminação dos indivíduos em decorrência do foco na razão/ilustração, seria desvirtuada ao ponto de se transformar completamente, terminando por conduzir à subordinação do homem à instrumentalização da razão e ao domínio da técnica.

Razão e técnica encontrar-se-iam, pois, a serviço da lógica capitalista de maximização do lucro e aumento da produtividade através da otimização racional da relação entre meios e fins, afetando todas as esferas sociais. $\mathrm{Na}$ verdade, quando investigou a relação entre capitalismo e religião, desencantamento e racionalização, Weber já havia apontado para a correlação entre a ética protestante e os valores típicos da classe burguesa e, por conseguinte, do modo de produção capitalista, superestimando o trabalho, enquanto elemento central da

\footnotetext{
${ }^{1}$ Assim explica a socióloga Barbara Freitag (2004, p. 10): Com o termo 'Escola de Frankfurt' procura-se designar a institucionalização dos trabalhos de um grupo de intelectuais marxistas, não ortodoxos, que na década dos anos 20 permaneceram à margem de um marxismo-leninismo 'clássico', seja em sua versão teóricoideológica, seja em sua linha militante e partidária.

${ }^{2}$ É Freitag (2004, pp. 36-37) quem também resume um pouco da compreensão das bases iniciais da "Teoria Crítica" nos seguintes termos: "Em seu artigo, 'Teoria Tradicional e Teoria Crítica', de 1937, reeditado posteriormente nos dois volumes intitulados Teoria Crítica (1968), Horkheimer abre uma discussão que lançará o moderno pensamento sociológico em um profundo dilema [...] não se trata, como no caso de Weber, [...] de uma questão meramente metodológica. Trata-se [...] de uma questão em última instância ontológica. [...] Ao contrapor a filosofia de Descartes (teoria tradicional) ao pensamento de Marx (teoria crítica) descreve as características as características essenciais de cada vertente do pensamento, seus objetivos e sua forma de atuação, denunciando o caráter sistêmico e conservador do primeiro, e sublinhando enfaticamente a dimensão humanística, emancipatória do segundo". (grifos do original).
} 
vida humana, independentemente de suas circunstâncias, e condenando profundamente o ócio - este, sim, agora visto como pecado, e não mais a busca por lucro, antes considerada usura e condenada pela igreja católica.

Sobre a razão instrumental também se debruçou Jürgen Habermas, herdeiro da Escola de Frankfurt, ainda que dela tenha se distanciado depois de alguns anos. Quanto ao processo de racionalização estudado por Weber, explica Habermas (2002, p. 53):

\begin{abstract}
Max Weber introduce el concepto de racionalidad para definir la forma de la actividad económica capitalista, del tráfico social regido por el derecho privado burgués, y de la dominación burocrática. «Racionalización» significa en primer lugar la ampliación de los ámbitos sociales que quedan sometidos a los criterios de la decisión racional. Paralelamente a esto corre, en segundo lugar, la industrialización del trabajo social, con la consecuencia de que los criterios de la acción instrumental penetran también en otros ámbitos de la vida (urbanización de las formas de existencia, tecnificación del tráfico social y de la comunicación). En los dos casos se trata de la implantación del tipo de acción que es la racional con respecto a fines: en el segundo caso esa implantación afecta a la organización de los medios, y en el primero a la elección entre posibles alternativas. Finalmente, la planificación puede ser concebida como una modalidad de orden superior de la acción racional con respecto a fines: tiende a la instauración, mejora o ampliación de los sistemas de acción racional mismos. (grifamos).
\end{abstract}

Já sobre a própria razão técnica, citando Herbert Marcuse, outro sociólogo alemão, indica Habermas (2004, p. 55):

\begin{abstract}
En su crítica a Max Weber, Marcuse llega a la siguiente conclusión: «El concepto de razón técnica es quizá él mismo ideología. No sólo su aplicación sino que ya la técnica misma es dominio sobre la naturaleza y sobre los hombres: un dominio metódico, científico, calculado y calculante. No es que determinados fines e intereses de dominio sólo se advengan a la técnica a posteriori y desde fuera, sino que entran ya en la construcción del mismo aparato técnico. La técnica es en cada caso un proyecto histórico-social; en él se proyecta lo que una sociedad y los intereses en ella dominantes tienen el propósito de hacer con los hombres y con las cosas. Un tal propósito de dominio es material, y en este sentido pertenece a la forma misma de la razón técnica»
\end{abstract}

O que se pode inferir do exposto é que a racionalização afetou diversos âmbitos sociais, limitando o agir consciente do indivíduo, à medida que as escolhas tidas como racionais se lhe impunham. Tais escolhas derivavam do cálculo racional e do predomínio da técnica. A razão técnica, portanto, ainda que considerada a máxima expressão da razão humana por muito tempo, representava, segundo Marcuse e Habermas, verdadeira ideologia - compreensão de mundo voltada para a dominação velada e imposição de um determinado padrão social, comportamental etc., visando sempre o atendimento aos fins erigidos pelo modo de produção e não pelos próprios indivíduos, estes últimos, sem tempo e sem estímulo à reflexão, encontravam-se perdidos em sua alienação. 
Carlos Drummond de Andrade (1993, p. 31), nos versos do poema "Elegia 1938" a seguir transcritos, conseguiu captar com bastante precisão a condição do indivíduo imerso no contexto do predomínio da razão instrumental, a que se chamou ethos produtivo ou colonizatório (GRANT, 2012), isto é, um modo de vida colonizado pelo imperativo da técnica, da produtividade, da repetição acrítica, alienada, da existência mecânica e operacional descrita, por exemplo, pela concepção determinista e mecanicista de mundo dominante no século XIX e ainda por bastante tempo no século XX:

Trabalhas sem alegria para um mundo caduco, onde as formas e as ações não encerram nenhum exemplo. Praticas laboriosamente os gestos universais, sentes calor e frio, falta de dinheiro, fome e desejo sexual. [...] Caminhas entre mortos e com eles conversas sobre coisas do tempo futuro e negócios do espírito. [...]

Um dos âmbitos afetados pela racionalização foi a própria arte, em especial a música, circunstância sobre a qual expõe Stephen Nachmanovitch (1993, p. 20) nos seguintes termos:

No século XIX, o surgimento da sala formal de concertos pôs fim à improvisação. A Era Industrial trouxe consigo uma valorização excessiva da especialização e do profissionalismo em todos os cantos da atividade. Os músicos, em sua grande maioria, viram-se restringidos a executar nota por nota as partituras escritas por um grupo de compositores que de alguma forma tinham acesso ao divino misterioso processo de criação. A composição e a execução foram se separando gradualmente, em prejuízo de

ambas. Formas clássicas e populares também foram se afastando cada vez mais, novamente em prejuízo de ambas. $\mathrm{O}$ novo e o velho perderam contato e continuidade. Entramos num período em que os frequentadores de concertos passaram a acreditar que os bons compositores estavam mortos. (grifamos).

Com a crítica à razão instrumental, contudo, surgiram alternativas. A própria "Dialética do Esclarecimento" representou uma, assim como, em seguida, a "Teoria da Ação Comunicativa" de Habermas, dentre tantas outras, mas o foco deste trabalho será a "entrega", para o "Ser Criativo", teorizado por Stephen Nachmanovitch, e o conceito de "nada", da metafísica de Martin Heidegger, elementos integrantes da proposta de construção de um novo ethos a serem explorados nos próximos tópicos.

Nada obstante, antecipando a defesa do "ócio criativo", o qual suscita a associação entre o "vazio" referido no título deste trabalho e o seu potencial criativo, interessante concluir o presente tópico com uma ponderação de Domenico De Masi (2000, p. 18): “A sociedade industrial permitiu que milhões de pessoas agissem somente com o corpo, mas não 
lhes deixou a liberdade para expressar-se com a mente. [...] A sociedade pós-industrial oferece uma nova liberdade: depois do corpo, liberta a alma". Agora, como seria possível "libertar a alma"?

\section{A "ENTREGA" E O "DESAPARECER" PARA O "SER CRIATIVO" TEORIZADO POR STEPHEN NACHMANOVITCH: O SAMADHI COMO CAMINHO}

Como foi visto no tópico anterior, o paradigma da razão técnica ou instrumental, consolidado no processo de racionalização pelo qual passou a modernidade, instituiu a padronização e a repetição acrítica, provocando a alienação e condenando profundamente o ócio. O que ficou, portanto, enraizado no senso comum ou inconsciente coletivo foi a frequente e intensa associação entre ócio e perda de tempo, ócio e nada, no sentido de vazio produtivo. É justamente com o propósito de revisão destas associações que se faz o convite para as reflexões a seguir.

Em primeiro lugar, imperioso se faz esclarecer, desde já, o que se está a compreender por “ócio". Nesse contexto, bastante elucidativa é a explicação de Domenico De Masi (2000, p. 17), ao indicar que o estado de ócio não significa "não fazer nada" e que "não fazer nada" é muito menos prazeroso do que experimentar um estado verdadeiramente criativo em momentos de "ócio". Isso porque, se se resgatar o sentido grego da palavra, o ócio estava diretamente ligado às atividades essencialmente reflexivas, pensantes e produtivas - no sentido da criação e não da mera transpiração -, tais como a filosofia, a poesia e a política, por exemplo.

Pois bem, mas a pergunta que ficou em aberto foi “como é possível 'libertar a alma'?”. Noutros termos, como é possível alcançar este estado de ócio criativo, transcendendo os limites da

técnica e da mera reprodução, muitas vezes inconsciente e disfarçada de produção científica? Como é possível descolonizar o pensamento, transformando o ethos colonizatório em um novo ethos, o qual já se compreendeu como civilizacional ou civilizatório ${ }^{3}$ (GRANT, 2012),

\footnotetext{
${ }^{3}$ Conforme já se defendeu em pesquisas anteriores: “[...] o que se pretende neste projeto é discutir um novo modo de pensar o fazer científico em Direito, como um educar pela pesquisa, nas palavras de Pedro Demo (2007), ético, para além de técnico, como uma razão emancipatória, no sentido de Boaventura de Sousa Santos (2005), ou um ethos civilizatório, isto é, crítico, reflexivo, intersubjetivo, complexo" (GRANT, 2012, p. 02 grifos do original e grifo nosso).
} 
mas que, aqui, estará focado no aspecto produtivo-criativo e lúdico ${ }^{44}$ ?

É neste ponto que se destaca um dos principais elementos identificados por Stephen Nachmanovitch ao tratar sobre o processo de criação em sua obra "Ser Criativo" (1993), qual seja: a entrega.

Para explicar o que significa a atitude da entrega, Nachmanovitch (1993, p. 130) relembra o quanto o indivíduo pode encarar ou até mesmo transformar o momento da criação em algo extenuante, difícil, complicado, complexo e praticamente impossível, ao focar, por demasiado tempo, por exemplo, em uma única forma de analisar o problema colocado, sobre o qual deseja refletir para encontrar uma solução criativa, ou mesmo após tentar variadas abordagens, encontrando, contudo, apenas frustração. São nestes momentos de maior dificuldade e bloqueio, quando se está prestes a perder as forças e desistir, que o indivíduo se depara com um profundo abismo e se sente compelido a saltar e lançar-se naquele imenso vazio. Esta é a atitude de entrega mencionada: o abdicar do controle, o "romper da armadura", o libertar-se das próprias amarras e perder-se de si, sem, de fato, abandonar-se por completo, pois o que, na verdade, se abandona é o que se era antes da abertura para o novo e o que fica é justamente a parte de si que está pronta para captar este novo, o clarão de compreensão que emerge do fundo da escuridão abissal em que o sujeito se lançou. É da entrega que nasce a solução, a resposta tão arduamente procurada e a inspiração para a criação.

Por ouro lado, no momento em que se ganha consciência sobre a importância da entrega para o processo criativo, é preciso também chamar a atenção para o fato de que não se trata de um passo deliberado e forçado, não é possível fingir a renúncia ao controle, de forma artificial e aparente, para que a solução se manifeste, conforme alerta o próprio Nachmanovitch (1993, p.130), ao concluir que "a entrega tem que ser genuína, espontânea, sincera: tenho que abandonar realmente qualquer esperança e qualquer medo, sabendo que nada tenho a ganhar ou a perder".

Daí a importância de investir reais esforços no que se chamou de "desaparecimento".

\footnotetext{
${ }^{4}$ Neste trabalho, sobretudo a partir das teorizações de Cipriano Luckesi (1998; s/d), considera-se a ludicidade como um estado do ser, que envolve plenitude e presença, sendo capaz despertar e desenvolver diferentes estados de consciência, do mais visível e material, relacionado ao corpo e ao agir, ao mais sutil e espiritual, relacionado ao sentir, ao entrar em contato consigo e à integração com o todo, desenvolvendo autoconsciência e consciência do uno. Dessa forma, o lúdico integra as dimensões corporal, emocional e espiritual do ser humano, até promover o alcance do

estágio mais sutil, que é o da consciência contemplativa, o qual, para Luckesi (1998, p. 26), corresponde a "um estado de consciência, através do qual entramos em contato com as compreensões mais fundamentais da existência. É onde nos abrimos para 'escutar o Ser', a essência de cada um de nós [...]. É [...] onde ocorre uma integração com o todo [...] sem perder-se".
} 
Explica Nachmanovitch (1993, p. 132): "para criar temos que desaparecer. Isso parece paradoxal, porque, quando [...] me sinto bloqueado, tenho a sensação de que não existe nada dentro de mim; acho que estou vazio. Mas na verdade não estou vazio, estou cheio de lixo!”. Ou seja, quando ingressa na missão de pensar sobre algo e criar o que quer que seja, o indivíduo carrega consigo toda uma visão de mundo pré-concebida, preconceitos, paixões, compulsões, ideologias, ilusões e afins, de modo que toda esta "bagagem" influencia fortemente na sua capacidade de vislumbrar uma saída para o problema que se colocou ou mesmo para conceber algo novo. Dessa forma, no momento em que o bloqueio se instaura, trazendo consigo uma grande sensação de "vazio criativo" ou um "nada produtivo", na verdade, há um "muito" de coisas se colocando entre o sujeito e o que ele precisa enxergar para sair da situação em que se encontra. Por isso, conclui Nachmanovitch (1993, p. 132), "todo esse lixo espiritual precisa ser descartado. Só uma entrega incondicional conduz ao verdadeiro vazio, e a partir desse vazio eu posso ser produtivo e livre".

Ao se falar e, mais ainda, ao se defender a importância do "vazio" para o "ser criativo", muito possivelmente se suscita certo medo, desconfiança ou, no mínimo, algumas ressalvas por parte de quem está entrando em contato com a proposta pela primeira vez, em razão, principalmente, da tradição referida no início do tópico de associação entre vazio, ócio e improdutividade. Todavia, são destes exatos momentos que advém a força necessária para direcionar o indivíduo à produção eficiente e à liberdade criativa. É quando não está mais atordoado pelo barulho desnorteador e bloqueante de suas compreensões pré-concebidas que o sujeito pode "ouvir" algo maior e mais profundo, entrando, assim, em contato com o que Nachmanovitch (1993, p. 39) chamou de intelleto $^{5}$, uma inteligência visionária, que permite enxergar além do padrão e do aparente, e que alguns associam ao grande fluxo de energia e conhecimento que conecta a tudo e a todos no universo.

Algumas questões, entretanto, remanescem clamando por maior atenção: em que consiste este "desaparecer" e o que fazer para alcança-lo?

Para tratar do "desaparecimento" em si, Nachmanovitch (1993, p. 57) remete ao

\footnotetext{
${ }^{5}$ Conforme explica o autor: [...] Intelleto significa inteligência, não a inteligência meramente racional, mas a inteligência visionária, uma profunda visão dos padrões ocultos sob as aparências. Nesse aspecto o artista é um arqueólogo, que revela camadas cada vez mais profundas à medida que trabalha, que recupera não apenas antigas civilizações, mas algo que ainda está por nascer, algo nunca visto nem ouvido antes, a não ser pelo olho interior, pelo ouvido interior. Ele não está apenas removendo superfícies aparentes de um objeto externo, está removendo superfícies aparentes do Ser, revelando sua natureza original. [...] Quando temos uma inspiração, no amor, na criação, na música, na literatura, nos negócios, no esporte ou na meditação, estamos sintonizados com esse presente eterno, com o ambiente sempre mutável do conhecimento sobre a profunda estrutura de nosso mundo, com esse fluir eterno do Tao. (NACHMANOVITCH, 1993, pp. 39-42).
} 
brincar da criança, ao quanto ela se encontra plena, presente e envolvida na brincadeira, de modo que, de um lado, ela e o ambiente se fundem e, portanto, ela "desaparece" através e no ato de brincar, e, de outro, como consequência necessária e intrínseca ao processo, a criatividade floresce, flui livremente. Daí também poder falar-se em um estado lúdico para o criar, na linha do que já foi referenciado, a partir do momento em que se assume a ludicidade como um estado do ser, envolvendo, sobretudo, plenitude e presença, além de íntima conexão entre o agir, o pensar e o sentir humanos. Assim descreve Nachmanovitch (1993, p. 57): “[...] Mente e sentido ficam por um momento inteiramente presos na experiência. Nada mais existe. Quando 'desaparecemos' dessa maneira, tudo à nossa volta se torna uma surpresa, nova e fresca. [...] Esse [...] estado mental é o mais favorável à germinação de um trabalho original".

A plenitude que a sincera entrega e o desaparecimento propiciam também pode ser compreendida nos seguintes termos:

[...] A intensidade da concentração e do envolvimento se mantém e cresce por si mesma, nossas necessidades físicas diminuem, nossa visão se estreita, e perdemos o sentido de tempo. Nos sentimos despertos, vivos: o esforço se torna facilidade. Nos perdemos em nossa própria voz interior, no manuseio de nosso instrumento, na percepção intuitiva das regras. Absorvidos no puro fascínio do jogo, nas texturas, na resistência, nas nuances e limitações do nosso meio de expressão, nos esquecemos do tempo e do lugar onde estamos. O substantivo "ser" se torna verbo. É desse fulgor de criação no momento presente que o trabalho e o prazer emergem. (NACHMANOVITCH, 1993, pp. 57-58).

Como alcançar um tal estado de entrega, desaparecimento e ludicidade? Os budistas, indica Nachmanovitch (1993, p. 58), "chamam esse estado de absorção e absoluta concentração de samadhi. [...] Quando abandonamos nosso apego ao ego, entramos num estado que é ao mesmo tempo de transe e de alerta". O conceito de samadhi utilizado por Nachmanovitch representa, pois, uma "chave" importante de acesso ao referido estado, e a meditação tem sido o caminho mais difundido, embora qualquer outra atividade, realizada nas condições acima descritas, isto é, com inteireza, envolvimento e completa absorção, possa levar ao samadhi - até mesmo o "trabalho", seja ele qual for, afinal, são nestes momentos que a técnica, mais relacionada ao mundo da produtividade capitalista e, pois, do trabalho, e a arte, mais fortemente atrelada ao contexto da fruição meramente estética, se (con)fundem, conforme se verá a seguir. 


\title{
5. A QUESTÃO DA TÉCNICA PARA MARTIN HEIDEGGER: ARMAÇÃo VERSUS ARTE - INTRODUZINDO A DISCUSSÃO AO PENSAMENTO HEIDEGGERIANO
}

Ao refletir sobre a "questão da técnica", o filósofo alemão Martin Heidegger (2007) lançou novas luzes sobre o debate já evidenciado no tópico em que se discorreu sobre a razão técnica ou instrumental. Isso porque, ao indagar pela "essência" da técnica, de modo a estabelecer uma relação livre com ela, permitindo o seu ingresso na "clareira do dasein" (isto é, no âmbito de conhecimento daquele que conhece a partir de sua experiência no mundo), com a atitude de "abertura" ${ }^{6}$ necessária, o filósofo permitiu a percepção de que não há nada de técnico na essência da técnica e que é justamente a sua aparente "neutralidade" e "tecnicidade" que afastam o sujeito pensante da correta compreensão, de modo a tornar-se um escravo da técnica, colonizado por ela.

Alerta Heidegger (2007, p. 376):

\begin{abstract}
Assim, pois, a essência da técnica também não é de modo algum algo técnico. E por isso nunca experimentaremos nossa relação para com a sua essência enquanto somente representarmos e propagarmos o que é técnico, satisfizermo-nos com a técnica ou escaparmos dela. Por todos os lados, permaneceremos, sem liberdade, atados a ela, mesmo que a neguemos ou a confirmemos apaixonadamente. Mas de modo mais triste estamos entregues à técnica quando a consideramos como algo $\underline{\text { neutro; }}$ pois essa representação, à qual hoje em dia especialmente se adora prestar homenagem, nos torna completamente cegos perante a essência da técnica. (grifamos).
\end{abstract}

Ao prosseguir, portanto, com a sua investigação, Heidegger (2007, p. 385) cria condições favoráveis ao questionamento da técnica enquanto "armação", isto é, enquanto um modo muito específico de "desabrigar" (“desocultar”) da modernidade:

Armação significa a reunião daquele pôr que o homem põe, isto é, desafia para desocultar a realidade no modo do requerer enquanto subsistência. Armação significa o modo de desabrigar que impera na essência da técnica moderna e não é propriamente nada de técnico. Ao que é técnico pertence, em contrapartida, tudo o que conhecemos como sendo estruturas, camadas e suportes, e que são peças do

\footnotetext{
${ }^{6}$ Toda relação de abertura para algo, explica Martin Heidegger (1943, p. 334), “[...] é um comportamento. A abertura que o homem mantém se diferencia conforme a natureza do ente e o modo do comportamento. Todo trabalho e toda realização, toda ação e toda previsão, se mantém na abertura de um âmbito aberto no seio do qual o ente se põe propriamente e se torna suscetível de ser expresso naquilo que é e como é. Isto somente acontece quando o ente mesmo se propõe, na enunciação que o apresenta, de tal maneira que esta enunciação se submete à ordem de exprimir o ente assim como é. Na medida em que a enunciação obedece a tal ordem, ela se conforma ao ente. O dizer que se submete a tal ordem é conforme (verdadeiro). O que assim é dito é conforme (verdadeiro)".
} 
que se denomina como sendo uma montagem. Esta, contudo, com todo o seu conjunto de peças, recai no âmbito do trabalho técnico, que sempre corresponde apenas ao desafio da armação, mas nunca perfaz esta ou mesmo a efetua.

Ocorre que a técnica, como armação, impede "o aparecer e o imperar da verdade". Com essa conclusão, Heidegger (2007, p. 390) entende que não é a técnica, em si, que é má, mas a forma como vinha sendo compreendida (o seu “desabrigar"), e conclui afirmando que:

\begin{abstract}
A ameaça dos homens não vem primeiramente das máquinas e aparelhos da técnica cujo efeito pode causar a morte. A autêntica ameaça já atacou o homem em sua essência. O domínio da armação ameaça com a possibilidade de que a entrada num desabrigar mais originário possa estar impedida para o homem, como também o homem poderá estar impedido de perceber o apelo de uma verdade mais originária. Assim, pois, onde domina a armação, há perigo em sentido extremo.
\end{abstract}

A técnica enquanto armação impede a busca do indivíduo pela verdade enquanto alétheia ${ }^{7}$

-, enquanto um constante "desvelar" ("desabrigar"), que, ao fazê-lo, oculta ("vela") algo, de modo que a busca necessita prosseguir, uma vez que o caminho do pensamento reflexivo, investigativo, envolve um "caminhar de trás para frente", daquilo que é mais evidente até a sua "essência", um acontecer mais original e primeiro.

A "questão da técnica", portanto, que intitula o texto ora discutido, aponta para os riscos da "essencialização" da verdade na técnica, interrompendo o fluxo do desvelar e velar (“desabrigar e ocultar”) da verdade (“alétheia”). Ressalta Heidegger (2007, pp. 394-395), “a essencialização da técnica ameaça o desabrigar [...]. A empresa humana nunca pode sozinha banir este perigo. Mas, a meditação humana pode refletir sobre o fato de que tudo o que salva necessita de uma essência superior à do perigo, embora a ela aparentada”. Ou seja, onde reside o perigo, também se encontra a solução. É o questionar pela essência da técnica que leva à identificação da "armação", do risco que esse modo de "desabrigar" representa, e à possibilidade do rompimento desta prisão, com o consequente desenvolvimento da compreensão da técnica noutro âmbito, retomando as suas origens gregas, isto é, como arte,

\footnotetext{
${ }^{7}$ Sobre o conceito de "alétheia", expõe Heidegger (1943, p. 336) que: “[...] Se traduzimos a palavra alétheia por "desvelamento", em lugar de "verdade", esta tradução não é somente mais "literal", mas ela compreende a indicação de repensar mais originalmente a noção corrente de verdade como conformidade da enunciação, no sentido, ainda incompreendido, do caráter de ser desvelado e do desvelamento do ente. $\mathrm{O}$ entregar-se ao caráter de ser desvelado não quer dizer perder-se nele, mas se desdobra num recuo diante do ente a fim de que este se manifeste naquilo que é e como é, de tal maneira que a adequação apresentativa dele receba a medida.

Semelhante deixar-ser significa que nós nos expomos ao ente enquanto tal e que transferimos para o aberto todo o nosso comportamento. O deixar-se, isto é, a liberdade, é, em si mesmo, exposição ao ente, isto é, ek-sistente. A essência da liberdade, entrevista à luz da essência da verdade, aparece como exposição ao ente enquanto ele tem o caráter de desvelado".
} 
de modo a dar continuidade aos questionamentos, mantendo os mistérios próprios à busca pela verdade ${ }^{8}$.

Wálber Carneiro (2011, pp. 35-36), após analisar o mesmo texto, conclui que, de acordo com Heidegger, “[...] a técnica para os gregos não está relacionada, apenas, à 'palavra fazer na habilidade artesanal', [...] o que torna a produção algo poiético [criativo], diferenciando-se significativamente da técnica moderna, onde a tônica é o fazer a partir de uma reprodução não criativa”. Dessa forma, resta demonstrado um importante salto qualitativo na maneira de compreender a técnica e o seu uso, bem como o reflexo na compreensão do próprio trabalho, partindo da diferença entre o "fazer" (do homo faber) e o "criar" (do homo ludens), desde Aristóteles, à medida que a arte (e, por conseguinte, a técnica como arte e não mais como armação) estaria intrinsecamente relacionada ao "criar" e não ao "fazer" laboral.

Mas qual é, então, o papel do "nada" em toda esta discussão? Pois bem, se a técnica (antes reprodutiva) pode ser compreendida como arte (criativa) e este seria um caminho para não interromper o eterno jogo do desvelar e velar da busca pela verdade enquanto alétheia, o "nada" aparece como forma de colocar a questão metafísica, permitindo a compreensão de como se dá, justamente, a confrontação com a totalidade do ente (o que as coisas aparentam ser) e o enxergar além, para além do ente, o que representa a finalidade da própria interrogação metafísica e, ao mesmo tempo, a experiência necessária para transcender os limites daquele aparente, do pré- concebido, e, assim, acessar a fonte criativa. O "lançar-se no nada", é o que se pretende defender, seria o equivalente filosófico da tentativa de alcançar o fluxo da energia criadora (Tao) através do samadhi budista.

\footnotetext{
${ }^{8}$ Heidegger (2007, p. 396) conclui a sua reflexão sobre "A questão da técnica" nos seguintes termos: "Porque a essência da técnica não é nada de técnico, por isso a meditação essencial sobre a técnica e a discussão decisiva com ela devem acontecer num âmbito que, por um lado, está aparentado com a essência da técnica e, por outro lado, no entanto, é fundamentalmente diferente dela. Um tal âmbito é a arte, mas somente quando a meditação artística, por seu lado, não se trancar à constelação da verdade, pela qual questionamos. Questionando, portanto, testemunhamos a crise de que ainda não experimentamos a essencialização da técnica diante da pura técnica, que não protegemos mais a essencialização da arte diante da pura estética. Contudo, quanto mais de modo questionador refletirmos sobre a essência da técnica, tanto mais cheia de mistério será a essência da arte. Quanto mais nos aproximarmos do perigo, de modo mais claro começarão a brilhar os caminhos para o que salva, mais questionadores seremos. Pois o questionar é a devoção do pensamento.”.
} 
6. A “QUESTÃO DO NADA" COMO UMA QUESTÃO METAFÍSICA: O “LANÇAR-SE NO NADA" DA METAFÍSICA HEIDEGGERIANA COMO EQUIVALENTE FILOSÓFICO DO SAMADHI BUDISTA

No texto "Que é Metafísica" (1929), Heidegger não se propõe a falar sobre a metafísica, mas, sim, a colocar uma questão propriamente metafísica e, assim, conduzir-se para o interior dela, permitindo que a metafísica em si se revele para além da aparência. Ele divide, então, o texto em três partes, quais sejam: a elaboração da interrogação metafísica, o seu desenvolvimento e, por fim, naturalmente, a apresentação da resposta. Qual seria tal indagação metafísica senão a pergunta pelo "nada".

A ciência, que, através da referência ao mundo, procura um ente (manifestação do "ser" das coisas) para torná-lo objeto de investigação, adotando um comportamento tendente a fornecer ao ente estudado uma primeira e última palavra, provoca, em última instância a irrupção de um ente entre outros que é o próprio homem, o ser que conhece e "faz ciência", permitindo, inclusive, que, em reflexão filosófica e epistemológica, chegue a si mesmo.

Por estar sempre voltada ao ente - e para além dele, "nada" -, a ciência desinteressouse pela questão do nada, desprezando-o ao considera-lo apenas enquanto "negação", como "aquilo que não existe". A pergunta pelo "nada", portanto, aparece, a princípio, como uma contradição lógica, uma vez que, ao se perguntar por algo, pergunta-se o que algo "é", pressupondo que seja alguma coisa e, por conseguinte, que exista. Todavia, se antes e pressupunha que o "nada" era negação, como poderia algo "não ser" e "ser" ao mesmo tempo? Isso tornaria a pergunta uma impossibilidade lógica.

Heidegger apresenta, contudo, outro caminho para o raciocínio: para que seja possível ao menos formular a questão do nada, ele defende que se supere o bloqueio diante da aparente impossibilidade lógica da indagação e avance perguntando, pois, onde o "nada" pode ser encontrado, se se está a perguntar pelo que ele é, pressupondo que exista e possa ser, então, localizado em algum lugar.

Pois bem, se se assume que, de fato, o "nada" é uma negação, para que se tenha um ponto de partida, qual seja, o da compreensão até o momento mais difundida, poder-se-ia concluir que o "nada" seria "a plena negação da totalidade do ente". Dessa forma, "a totalidade do ente deve ser previamente dada para que possa ser submetida enquanto tal simplesmente à negação, na qual, então, o próprio nada se deverá manifestar” (HEIDEGGER, 1929, p. 4). 
Como acessar, entretanto, o ente em sua totalidade, sobretudo se se está constantemente "preso" a um aspecto ou outro de um ente específico ou a uma forma específica ou outra de compreendê-lo? Heidegger responde a esta igualmente aparente impossibilidade reflexiva afirmando que se, de um lado, seria realmente impossível ao indivíduo acessar a totalidade do ente, por outro, seria possível a ele perceber-se em meio ao ente que se desvela em sua totalidade e, neste meio, ter um vislumbre daquela mesma totalidade.

Os momentos de profundo tédio e profunda alegria seriam os responsáveis por ocasionar estes vislumbres, ao distrair, por um momento, o indivíduo daquilo que vinha focando o seu interesse e compreensão (um domínio particular do ente), permitindo-lhe o contato com a "unidade na totalidade", o ente desvelado em sua totalidade?:

A percepção e a compreensão primeiras da totalidade do ente não acontecem por meio do recurso ao pensamento racional, simplesmente, mas, sobretudo, por conta do sentimento ${ }^{10}$ que estimula aquela mesma percepção. E se o tédio e a alegria favorecem o contato com a totalidade do ente, ocultam justamente o "nada" como sua negação. Qual seria, então, a "disposição de

humor" ou sentimento capaz de fazer emergir precisamente aquilo que fora ocultado na placidez do tédio ou na profusão da alegria? A angústia é a resposta, porém não entendida como "temor" ou "ansiedade":

Este acontecer é possível e também real - ainda que bastante raro - apenas por instantes, na disposição de humor fundamental da angústia. Por esta angústia não entendemos a assaz frequente ansiedade que, em última análise, pertence aos fenômenos do temor que com tanta facilidade se mostram. $\underline{\text { A angústia é }}$

\footnotetext{
${ }^{9}$ Explica Heidegger: "Parece, sem dúvida, que, em nossa rotina cotidiana, estamos presos sempre apenas a este ou àquele ente, como se estivéssemos perdidos neste ou naquele domínio do ente. Mas, por mais disperso que possa parecer o cotidiano, ele retém, mesmo que vagamente, o ente numa unidade de "totalidade". Mesmo então e justamente então, quando não estamos propriamente ocupados com as coisas e com nós mesmos, sobrevém-

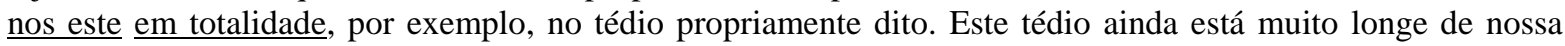
experiência quando nos entedia exclusivamente este livro ou aquele espetáculo, aquela ocupação ou este ócio. Ele desabrocha se "a gente está entediado". O profundo tédio, que como névoa silenciosa desliza para cá e para lá nos abismos da existência, nivela todas as coisas, os homens e a gente mesmo com elas, numa estranha indiferença. Esse tédio manifesta o ente em sua totalidade. Uma outra possibilidade de tal manifestação se revela na alegria pela presença - não da pura pessoa -, mas da existência de um ser querido" (HEIDEGGER, 1929, pp. 5-6- grifamos).

${ }^{10}$ Sobre a importância dos sentimentos, afirma Heidegger (1929, p. 5): “[...] O sentimento de situação da disposição de humor não revela apenas, sempre à sua maneira, o ente em sua totalidade. Mas este revelar é simultaneamente - longe de ser um simples episódio - um acontecimento fundamental de nosso ser-aí. O que assim chamamos sentimentos não é um fenômeno secundário de nosso comportamento pensante e volitivo, nem um simples impulso causador dele nem um estado atual com o qual nos temos que haver de uma ou outra maneira".
} 
radicalmente diferente do temor. Nós nos atemorizamos sempre diante deste ou daquele ente determinado que, sob um ou outro aspecto determinado, nos ameaça. O temor de... sempre teme por algo determinado. Pelo fato de o temor ter como propriedade a limitação de seu "de" (Wovor) e de seu "por" (Worum), o temeroso e o medroso são retidos por aquilo que nos amedronta. [...]. (HEIDEGGER, 1929, p. 5 - grifamos).

A angústia, ao ser entendida como "angústia por..." ou "angústia diante de...", isto é, traduzida na perfeita impossibilidade de determinação de sua causa ou objeto, corresponde, em verdade, ao que se poderia identificar, auxiliando o filósofo alemão, como uma "expectativa serena".

Ao compreender que a angústia manifesta o nada, Heidegger constatou que, quando isso acontece, “estamos suspensos na angústia”, uma vez que o nada provoca o desaparecer do ente em sua totalidade. Por isso, para seguir com a sua vida cotidiana sem ter de experienciar constantemente estes momentos de suspensão, o homem refugia-se em meio ao ente.

Por outro lado, se na angústia é possível experienciar, através do sentir, o "nada", isso não significa que ele possa ser apreendido na angústia ou se apresente enquanto ente, muito menos objeto ("essencializado") de investigação. O "nada" revela-se quando a totalidade do ente escapa; ou seja, através e na angústia, o "nada" se faz presente juntamente com a totalidade do ente. Não acontece, assim, na angústia, uma destruição do ente em sua totalidade, uma "negação" primeira, para que o "nada", então, se revele. Antes mesmo da negação, o nada já está presente.

O "nada", quando aparece "junto com" a totalidade do ente, provocando o seu escape, fuga ou estranheza, implica necessariamente um remeter sempre a tal totalidade do ente. Esta remissão faz parte da compreensão do próprio "nada", que passa a ser entendido como "nadificação", indicando que o "nada" não é nem destruição, nem negação do ente, mas o seu "nadificar", uma outra face do "ente":

[...] tal rejeição que afasta de si é, enquanto tal, um remeter (que faz fugir) ao ente em sua totalidade que desaparece. Esta remissão que rejeita em sua totalidade, remetendo ao ente em sua totalidade em fuga - tal é o modo de o nada assediar, na angústia, o ser-aí -, é a essência do nada: a nadificação. Ela não é nem uma destruição do ente, nem se origina de uma negação. [...]. (HEIDEGGER, 1929, p. 7 - grifamos).

Dizem que a hora mais escura do dia é a que vem logo antes do sol nascer. Pois bem, em analogia, seria possível afirmar que a escuridão do "nada" seria justamente o que permitiria o clarão da percepção do ente e o prosseguir no dasein (o compreender no mundo 
através da experiência):

Somente na clara noite do nada da angústia surge a originária abertura do ente enquanto tal: o fato de que é ente - e não nada. Mas este "e não nada", acrescentado em nosso discurso, não é uma clarificação tardia e secundária, mas a possibilidade prévia da revelação do ente em geral. A essência do nada originariamente nadificante consiste em: conduzir primeiramente o ser-aí diante do ente enquanto tal. (HEIDEGGER, 1929, p. 7 - grifamos).

A tarefa do "nada" seria apontar para as possibilidades de desvelamento do ente. É a revelação e o contato com o "nada", é o momento do "estar suspenso", que permite ao homem entrar em contato também com o ente em sua totalidade, compreendê-lo como puder, seja o ente ele mesmo ou outra manifestação no mundo:

\begin{abstract}
Ser-aí [dasein] quer dizer: estar suspenso dentro do nada. Suspendendo-se dentro do nada o ser-aí já sempre está além do ente em sua totalidade. Este estar além do ente designamos a transcendência. Se o ser-aí, nas raízes de sua essência, não exercesse o ato de transcender, e isto expressamos agora dizendo: $\underline{\text { se o ser-aí não }}$ estivesse suspenso previamente dentro do nada, ele jamais poderia entrar em relação com o ente e, portanto, também não consigo mesmo. Sem a originária revelação do nada não há ser-si-mesmo, nem liberdade. (HEIDEGGER, 1929, p. 7 - grifamos).
\end{abstract}

O "nada" promove a liberdade ao impulsionar o "ir-além" do que está manifestado, percebido ou compreendido como aparente. O "nada" e o ente, reitera-se, estão profunda e intimamente conectados, o que leva à resposta à questão do nada: "O nada não é nem um objeto nem um ente [...] é a possibilidade da revelação do ente enquanto tal para o ser-aí humano. O nada não é um conceito oposto ao ente, mas pertence originariamente à essência mesma (do ser). No ser do ente acontece o nadificar do nada" (HEIDEGGER, 1929, p. 7).

E por que o perguntar pelo nada seria uma pergunta eminente metafísica? Porque evoca a transcendência, como se disse, o "ir-além-do-ente" enquanto tal, que é justamente a finalidade da metafísica. Afinal:

O estar suspenso do ser-aí dentro do nada originado pela angústia escondida é o ultrapassar do ente em sua totalidade: a transcendência. Nossa interrogação pelo nada tem por meta apresentar-nos a própria metafísica. O nome metafísica vem do grego: tà metà physiká. Esta surpreendente expressão foi mais tarde interpretada como caracterização da interrogação que vai meta - trans além do ente enquanto tal. Metafísica é o perguntar além do ente para recuperá-lo, enquanto tal e em sua totalidade, para a compreensão. Na pergunta pelo nada acontece um tal ir para fora além do ente enquanto ente em sua totalidade. Com isto prova-se que ela é uma questão "metafísica". De questões deste tipo dávamos, no início, uma dupla característica: cada questão metafísica compreende, de um lado, sempre toda a metafísica. Em cada questão metafísica, de outro lado, sempre vem envolvido o ser-aí que interroga. (HEIDEGGER, 1929, p. 9). 
A "questão do nada" põe o indivíduo em contato com a própria tarefa da Filosofia, com a atitude filosófica do constante questionar e até mesmo com a reflexão filosófica, no sentido do questionar-se e do imperativo do "conhece-te a ti mesmo". Por isso a afirmação de que, por detrás de toda questão metafísica e no seu desenrolar, necessariamente se encontra o ser-aí que interroga. Dessa forma, a indagação pelo "nada" incita o questionamento de tudo o que é tido como dado, pré-concebido e/ou determinado, conduzindo à abertura para o novo, na busca, como se indicou antes, por alethéia, a verdade no seu eterno desvelar:

[...] Filosofia - o que nós assim designamos - é apenas o pôr em marcha a metafísica, na qual a filosofia toma consciência de si e conquista seus temas expressos. A filosofia somente se põe em movimento por um peculiar salto da própria existência nas possibilidades fundamentais do ser-aí, em sua totalidade. Para este salto são decisivos: primeiro, o dar espaço para o ente em sua totalidade; segundo, o abandonar-se para dentro do nada, quer dizer, o libertar-se dos ídolos que cada qual possui e para onde costuma refugiar-se sub-repticiamente; e, por último, permitir que se desenvolva este estar suspenso para que constantemente retorne à questão fundamental da metafísica que domina o próprio nada: Por que existe afinal ente e não antes nada? (HEIDEGGER, 1929, pp. 10-11 - grifamos).

No dia a dia, o indivíduo, como visto, encontra-se refugiado no ente, muitas vezes perdido, em meio ao ente revelado em sua totalidade, sem percebê-lo, alienado, estupidamente feliz em sua ignorância. Porém, a angústia o espreita, não no temor, nem na obstinação da pesquisa direcionada, da busca desenfreada por alguma verdade, geralmente uma verdade intencionada, moldada, mas precisamente na liberdade da profunda abertura ao novo.

A abertura ao novo evoca o prazer ou, ao menos, a esperança, não o medo, diante do desconhecido. Essa é a atitude propícia ao criar, à imersão no estado lúdico, ao perder-se dos limites de si para fundir-se plena e seguramente à imensidão do todo.

Se, por um lado, a vida ordinária se desenrola imersa nos limites e ilusões do senso comum, como decorrência, inclusive, do instinto de sobrevivência:

O senso comum tem sua própria necessidade; ele defende seu direito usando a única arma de que dispõe. Esta é o apelo à "evidência" de suas pretensões e críticas. A filosofia, por sua vez, jamais pode refutar o senso comum porque este não tem ouvidos para sua linguagem. Pelo contrário, ela nem deve ter a intenção de refutá-lo porque o senso comum não tem olhos para aquilo que a filosofia propõe para ser visto como essencial. Além do mais, nós mesmos nos movimentamos no nível de compreensão do senso comum, na medida em que nos cremos em segurança no seio das diversas "verdades" da experiência da vida, e da ação, da pesquisa, da criação e da fé. Nós mesmos participamos da revolta do "evidente" contra tudo o que exige ser posto em questão. (HEIDEGGER, 1943, p. 329grifamos). 
Por outro, sempre há aqueles que almejam a liberdade escondida por detrás da busca pelo conhecimento e pela criação:

[...] Antes de tudo isto (antes da liberdade "negativa" ou "positiva"), a liberdade é o abandono ao desvelamento do ente como tal. O caráter de ser desvelado do ente se encontra preservado pelo abandono ek-sistente; graças a este abandono, a abertura do aberto, isto é, a "presença" (o "aí"), é o que é. (HEIDEGGER, 1943, p. 336 - grifamos).

Ao analisar o texto "Que é Metafísica", de Martin Heidegger, a terapeuta junguiana Ercilia Magaldi (s/d) chegou a uma interessante conclusão sobre a importância da angústia e da confrontação com o "nada" para o amadurecimento e crescimento humanos:

[...] todo processo terapêutico positivo passa por um estágio de reconhecimento, seguindo- se um estágio de angústia que, se bem elaborado, não permitindo a fuga, mas o confrontamento com o nada, o paciente torna-se consciente de si; compreende-se como um ente em sua totalidade. Vemos ser a angústia um fator positivo e totalmente contrário à depressão, ansiedade, neurose e outros tantos sintomas que no linguajar comum se confundem. Se, através destes questionamentos, Heidegger trouxe grande benefício à filosofia e consequentemente a metafísica, demonstrando o grande valor do nada dentro desta ciência, muito, também, trouxe à psicologia junguiana, demonstrando que esse "monstro assustador" que é a angústia, e que cedo ou tarde se nos avizinha, é fator necessário de crescimento, de evolução enfim.

O "lançar-se no nada" é, portanto, o caminho para a liberdade. Sem o recear perante a angústia que se traduz em medo e, sim, substituindo-o pelo desejo de alcançar todo o potencial por detrás da angústia enquanto expectativa serena, prelúdio de possibilidades criativas. O mergulho no nada sem medo é o samadhi da Filosofia.

\section{CONSIDERAÇÕES FINAIS}

Ao longo deste trabalho, foi possível obter algumas importantes conclusões e estabelecer premissas necessárias para o que se pretende chamar de "vazio pleno", defendendo-o como possibilidade criativa.

Em primeiro lugar, precisou-se identificar e compreender um ethos que se consolidou no processo de racionalização da modernidade, mas em grande medida ainda se mostra predominante no modo de vida contemporâneo, qual seja, o ethos produtivo ou colonizatório, no âmbito do qual impera a razão técnica ou instrumental. Como atributos da razão instrumental, foi possível constatar o foco na produtividade, através da constante otimização da relação entre meios e fins, estes últimos alheios ao trabalhador comum, e a 
“essencialização" da técnica, que leva à reprodução acrítica e alienada.

Em segundo, investigou-se as potencialidades das noções de "entrega" e "desaparecimento", desenvolvidas por Stephen Nachmanovitch (1993), para o processo criativo. Como "entrega", compreendeu-se a atitude de "lançar-se no vazio", a fim de que o indivíduo se liberte de suas próprias amarras, isto é, de todas as compreensões preconcebidas, de todo o "lixo mental" que o estaria bloqueando em seu desejo de criar. O “desaparecimento", por sua vez, seria uma etapa necessária à "entrega", afinal, é quando o indivíduo "desaparece" que faz igualmente desaparecer suas preocupações, crenças limitantes, ilusões e tudo o mais que interferisse negativamente e, muitas vezes, inconscientemente, no ato criativo, permitindo o alcance e o fluir do intelleto, enquanto uma inteligência maior e visionária; não obstante, o "desaparecimento" não é completo, pois o que desaparece é a parte do indivíduo atrelada ao "velho" e o que fica é a parte de si preparada e aberta para o "novo", capaz de prosseguir na condução do processo criativo. O caminho para o "desaparecimento" e a "entrega" seria o samadhi, um estado, ao mesmo tempo, de transe e alerta, para o qual se propôs uma associação com o estado lúdico, teorizado sobretudo com base nos escritos de Luckesi (1998, s/d), ou seja, de plenitude e presença.

Em terceiro, resgatando-se a discussão sobre a questão da técnica, verificou-se que, por muito tempo, sobretudo na modernidade, a "essência" da técnica pôde ser compreendida como "armação", o que suscitou um grande perigo, o impedimento do "aparecer e imperar da verdade"; em outras palavras, a interrupção do fluxo do desvelar e velar da verdade ("alétheia"). A solução apontada foi a reinterpretação da "essência" da técnica como arte, remetendo à compreensão grega que via na produção humana algo muito mais poiético (criativo), do que meramente técnico- reprodutivo. Essa reflexão, assim como a crítica à razão instrumental e a busca pela atitude da "entrega" e do "desaparecimento" através do samadhi seriam fundamentais para a "descolonização" do pensamento, ao promover a ruptura com o ethos colonizatório e abrir espaço para possibilidades criativas.

Por fim, o "mergulho" na metafísica heideggeriana oportunizou não uma abordagem geral sobre a metafísica, mas o investimento na colocação de uma questão propriamente metafísica, qual seja, a pergunta pelo "nada". Ao refletir e buscar pelo "nada", ignorado pela ciência enquanto aquilo que simplesmente "não existe", mera "negação", foi possível superar a aparente impossibilidade lógica da pergunta, procurando-o, primeiro, na negação da totalidade do ente e, com isso, inquirindo sobre a própria possibilidade de contato com uma tal totalidade. Neste ponto, inferiu-se que o profundo tédio e a profunda alegria permitiriam 
o vislumbre do ente em sua totalidade ao distrair o indivíduo do foco em determinados e limitados aspectos do ente. A angústia, por outro lado, seria o sentimento que proporcionaria o contato com o "nada", mas não como medo ou ansiedade, e, sim, como impossibilidade de determinação (“angústia por...”). O "nada", na angústia, apareceria no escape da totalidade do ente, mas não como a sua negação ou destruição e, sim, junto ao ente, como a sua outra face, aquela, inclusive, que aponta para o ente e, em seu "nadificar", num eterno remeter, propicia que o indivíduo o conheça e conheça até mesmo a si mesmo no processo.

A questão do nada é uma questão metafísica por excelência porque põe em causa a totalidade e o próprio indivíduo que conhece, mas, acima de tudo, porque permite o "ir-alémdo- ente", do evidente ou aparente, ao apontar e permitir o contato com a totalidade do ente em um momento de suspensão, de vazio e impossibilidade de determinação, em um momento de angústia plácida. O "lançar-se no nada" da metafísica heideggeriana revela-se, pois, bastante compatível com o "lançar-se no vazio" da entrega no samadhi proposto por Nachmanovitch. Ambos acabam por invocar as potencialidades do ócio criativo, do estado lúdico, num "vazio" ou "nada" plenos; ou seja, num vazio que permite a conexão do indivíduo consigo, livre de amarras e bloqueios, e com a energia criadora (Tao) ou o intelleto, liberando possibilidades criativas, uma vez que o pensamento fora descolonizado e se realizou as condições para um novo ethos, um novo modo de vida, muito mais próximo dos potenciais do homo ludens - que indaga, reflete, se entrega e lança no "nada", sem medo, experienciando a plenitude e a presença - do que das limitações do homo faber - que, pressionado e alienado, apenas (re)produzia.

Em face de todo o exposto, nota-se que o recurso à experiência lúdica (integral, inclusiva, não competitiva, realizada no amor), sobretudo transdisciplinar, nos cursos de graduação em Direito, poderia oportunizar ao estudante vivências plenas e criativas, passíveis de despertar múltiplos estados de consciência e dimensões do humano, através da provocação ao pensar (já bastante trabalhado), sentir (que ainda necessita ser estimulado em um curso tão associado à racionalidade, austeridade e seriedade) e agir (não apenas de modo reprodutor e dogmático, mas reflexivo e complexo), potencializando-os com a incitação à reflexão filosófica (estado contemplativo), exercício da alteridade e preparo para o enfrentamento da diversidade e complexidade da vida contemporânea (não apenas às competências tecnológicas exigidas por uma noção restrita de mercado).

Somente um profissional formado no âmbito de uma proposta pedagógica delineada a partir das bases acima lançadas estaria de fato preparado para enfrentar os dilemas de uma sociedade plural, complexa e dinâmica, dispondo das ferramentas necessárias para criar 
novas soluções, não apenas reproduzir velhos brocados e dogmas ultrapassados, com a abertura, presença, inteireza e sensibilidade requeridas numa missão como esta.

\section{REFERÊNCIAS}

ANDRADE, Carlos Drummond de. Sentimento do Mundo. Rio de Janeiro: Record, 1993.

CARNEIRO, Wálber Araujo. Hermenêutica Jurídica Heterorreflexiva: uma teoria dialógica do Direito. Porto Alegre: Livraria do Advogado, 2011.

DE MASI, Domenico. O ócio criativo. Entrevista a Maria Serena Palieri. Rio de Janeiro: Sextante, 2000.

FREITAG, Barbara. A teoria crítica: ontem e hoje. São Paulo: Brasiliense, 2004.

GRANT, Carolina. Ética e Técnica na Pesquisa Jurídica: da proposta de um ethos civilizacional a uma análise da relação ética na pesquisa, sobretudo em face do advento de novas tecnologias. Relatório final de pesquisa do Programa Institucional de Bolsas de Iniciação Científica (PIBIC) 2011-2012. Salvador: UFBA, 2012.

HABERMAS, Jürgen. Ciência y técnica como “ideología”. 4a ed. Madrid: Tecnos, 2002.

HEIDEGGER, Martin. A questão da técnica. Scientice Zudia. Revista Latino-Americana de Filosofia e História da Ciência. Revista do Departamento de Filosofia - FFLCH - USP. São Paulo, v. 5, n. 3, p. 375-98, 2007.

Sobre a essência da verdade. (1943). Disponível em: <https://pt.scribd.com/doc/98600150/Heidegger-sobre-a-essencia-da-verdade>. Acesso em: 12 out. 2017.
Que
é Metafísica.
(1929).
Disponível em:

<www.unirio.br/cch/filosofia/Members/ecio.pisetta/SEM...e\%20Metafisica...pdf/.../file>. Acesso em: 12 out. 2017.

LUCKESI, Cipriano Carlos. Desenvolvimento dos estados de consciência e ludicidade. In: Cadernos de Pesquisa, FACED/UFBA, vol. 2, n. 21, 1998, pp. 9-25.

. Ludicidade e atividades lúdicas: uma abordagem a partir da experiência interna (s/d). Disponível em: <http://www.luckesi.com.br/artigoseducacaoludicidade.htm>. Acesso em: 12 out. 2017.

MAGALDI, Ercilia Simone Dalvio. O nada e seu valor metafísico. Disponível em:

$<$ http://www.ijep.com.br/index.php?sec=artigos\&id=37\&ref=-metaf\%C3\%ADsicaheideggeriana- e-a-ang\%C3\%BAstia>. Acesso em: 12 out. 2017.

MARX, Karl; ENGELS, Friedrich. Manifesto do Partido Comunista. In: Obras escogidas de Marx y Engels. Madrid: Fundamentos, 1975. 
NACHMANOVITCH, Stephen. Ser criativo: o poder da improvisação na vida e na arte. São Paulo: Summus, 1993.

QUINTANEIRO, Tania; BARBOSA, Maria Ligia de Oliveira; OLIVEIRA, Márcia Gardência Monteiro de. Um toque de clássicos: Marx, Durkheim, Wever. $2^{\mathrm{a}}$ ed. Belo Horizonte: Editora UFMG, 2003.

WEBER, Max. A ciência como vocação. In: GERTH, Hans; MILLS, Wright. Max Weber. Ensaios de Sociologia. Tradução de Waltensir Dutra. Rio de Janeiro: Zahar, 1979. 